\title{
Imagem: arqueologia e conceitos
}

Alberto KLEIN 


\section{Resumo}

Este trabalho tem o objetivo de fazer um percurso sobre os diversos conceitos e classificações da imagem, além de fazer uma análise de sua presença no universo midiático contemporâneo. $\mathrm{Na}$ segunda parte pretende-se investigar as raízes da imagem na pré-história e sua associação com o fenômeno da magia e da religião.

\section{Pálavrás-chave}

imagem, mídia, religião, magia

\section{Abstract}

The goal of this paper is to highlight various concepts and classifications of the image and to analyse its presence in the contemporary mediatic universe. In the second part, this work intends to research the roots of the image in the pre-history of mankind and to study its association with the phenomenon of magic and religion.

\section{Key words}

imagem, media, religion, magic 


\section{Televisão e hábito}

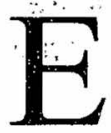

m princípió, imagem pode ser tudo que se dirige ao olhar. Qualquer sinal que incide no glóbo ocular passa pór processos quimicos e nêrvosos ate à fớmação visual de um determinado objeto que, em um determinado instante, vemos. Todo o universo de informações què se apresenta à visão humana passa a ser absorvido como imagem. Sobre este processo de apresentação imagética do mundo, Jacques Aumont afirma:

Assim, a percepção visual é o procesśamento, em etapas sucessivas, de uma informação que nòs chega por intermédio da luz que entra em nossos olhos. Como toda informação, esta é codificada - em um sentido que não é o da semiologia: os códigos são, aqui, regras de transformação naturais (nem arbitrárias, nem convencionais) que determinam a atividade nervosa em função da informaçãó contida na luz. (1993, p.22)

O ùso da palavira imagem não se limitâ, entretanto, ao já infinito universo das coisas capturadás pela visão. Afinal, criamos imagens mentais de objetos invisíveis, que muitas vèzes nunca irão se materializar diante de nossos olhos. $O$ conjunto destas imagens compõe aquilo que chamamos imaginário. Não se trata de um universo reduzido à ficção, âté porque as imagens produzidas pelo homem acabam por refazer o próprio homem. O que vemos, portanto, pode ser aquilo que também nos olha, parafrảseando uma expressão usada por George Didi-Huberman (1992). Depois de criar nošsos 
deuses, delegamos a eles o poder de nos recriar. É assim que Edgar Morin coloca o imaginário, como uma estrutura antagonista e complementar daquilo que chamamos real, e sem a qual, sem dúvida, não haveria o real para o homem, ou antes, não haveria realidade humana (1997, p.80). Com os olhos fechados formamos imagens oníricas. Experimentamos um mundo impossível através das imagens produzidas pelos sonhos (até mesmo por aqueles vivenciados na vigília) e, com elas, alimentamos o nosso imaginário. Não é por acaso que Ivan Bystrina coloca o sonho como uma das raízes transformadoras da cultura, que ele denomina Segunda Realidade. Ele irriga a produção de novos textos culturais, inspirando a criação de novas imagens. Neste mesmo sentido, Morin afirma:

(O imaginário) dá uma fisionomia não apenas a nossos desejos, nossas aspirações, nossas necessidades, mas também a nossas angústias e temores. Liberta não apenas nossos sonhos de realização e felicidade, mas também nossos monstros interiores, que violam os tabus $e$ as leis, trazem a destruição, a loucura ou o horror. Não só delineia o possível e o reálizável, mas cria mundos impossíveis e fantásticos. (1997, p.80)

O imaginário faz-se concretamente visível nos objetos da arte e da religião. Damos forma a pinturas, esculturas e desenhos em nossos sonhos e pesadelos. Traçamos a físionomia dos nossos deuses, fazendo-os à nossa imagem e semelhança. A imaginação humana não se prendeu a uma virtualidade mental, mas se inscreveu visivelmente, através do espetáculo da magia, da religião e da arte, em nossa realidade. Assim, devemos reconhecer a dupla natureza das imagens criadas pelo homem: mental e material.

Dentro do universo das imagens produzidas materialmente, podemos identificar naturezas muito diversas, que variam conforme seu material ou seu suporte tecnológico. Assim, temos esculturas, pinturas, grafite, bordados, estampas, fotografias, cinema, imagens de TV, infografias, holografias etc. Notamos que a vertiginosa evolução tecnológica na qual nossa cultura está inserida apresenta-nos 
um mundo que se multiplica a cada dia na forma de imagens em diferentes suportes. Neste sentido, tornam-se cada vez mais acessíveis gadjets como palm tops, celulares com acesso à Internet e que tiram fotos, assim como tecnologias de ponta, como a Realidade Virtual. Há também promessas para um futuro muito próximo quanto à utilização de hologramas e nanorrobôs (que serão literalmente ingeridos) como meios de comunicação interpessoal.

Do mesmo modo que variam os suportes, abre-se um leque de diferentes funções assumidas pelas imagens. Elas podem cumprir um fim religioso ou mágico, constituindo-se um símbolo ritualístico; como vimos, provavelmente este foi o primeiro horizonte da criação das primeiras imagens. Assumem mais tardiamente uma dimensão puramente estética, e aí estamos diante do valor artístico que salta das pinturas e esculturas e outras formas de artes visuais. Aqui, o ritual cede ou se torna residual nas formas profanas do culto à arte. Conforme Walter Benjamin (1969, p.224), o valor de culto de uma obra é sobreposto por seu valor de exposição, em uma era em que prevalecem mecanismos de reprodução mecânica da imagem, principalmente com a fotografia e o cinema.

Pela primeira vez na história, a reprodução mecânica emancipa a obra de arte de sua dependência parasitica do ritual. (...) a obra de arte torna-se uma obra de arte projetada para a reprodutibilidade ${ }^{1}$ (1969, p.224)

Morin (1997, p.77) vai tratar da experiência estética tanto na arte como na cultura de massa como uma "degradação" da participação religiosa. Enquanto nesta última, o mergulho na imagem representaria uma experiência de um imaginário que se torna mais real do que o próprio real, assistir a um filme ou a uma novela designa uma experiência que se situa um degrau abaixo da participação mágica e religiosa. Neste caso, rege uma dupla consciência do espectador, este pode ser intensamente absorvido pela obra, apesar do imaginário ser apenas tomado como imaginário.

1 Tradução do autor deste trabalho. 
Devemos também reconhecer muitas outras funções da imagem no contexto da cultura de massa. Ela se restringe a:uma finalidade informativa em fotos e charges de jornais, revistas, mesmo que se oriente por critérios estéticos:-As imagens; do mesmo modo, servem de passatempo, distração; entretenimento nas mais diversas produções nos meios de comunicação de massa: Orientam-nos para o consumo, comø o fazem as fotografias publicitárias, comerciais de televisão, assim como a floresta de outdoors, painéis eletrônicos, banners, e tantos outros suportes imagéticos que encobrem o espaço urbano.

As diferentes naturezas, origens, suportes e funções demonstram como esse conceito é complexo e escorregadio. $O$ esforço de análise e classificação das imagens está no domínio de diversas áreas do conhecimento, tais como: Filosofia, Estética, Psicologia, Comunicação, Antropologia'; Teologia, entre outras. A natureza das imagens é amplamente investigada pela física e pélas neurociências. A esta última estão vinculados trabalhos instigantes do neurologista norte-americano Oliver Sacks, um notório campeão de vendas, e do neurocientista português Antônio Damásio.

No final do livro O Mistério da Consciência, Damásio preocupa-se em discorrer sobre conceitos usados ao longo de sua obra. O termo imagem, para o neurocientista português, é empregado no sentido de padrão mental, podendo se remeter a processos conscientes ou inconscientes: Imagens mentais não se restrigem, conforme Damásio; à percepção visual; elas podem cobrir todo espectro sensorial. Poderíamos, assim, falar de imagens táteis ou olfativas ${ }^{3}$. A própria mente deveria ser entendida como um processo ligado a um fluxo contínuo de imagens. Sobre como se dá este fluxo o autor escreve:

$O$ processo que chegamos a conhecer como mente quando imagens mentais se tornam nossas, como

2. Etienne Samain, em um interessante ensaio chamado "Para que a antropologia consiga tornar-se visual", analisa a possibilidade de se fazer antropologia através da fotografia.

3 Embora haja uma aproximação com o conceito de ícone em Peirce, Damásio está tratando exclusivamente de imagens mentais. 
resultado da consciência, é um fluxo contínuo de imagens, e muitas delas se revelam logicamente interrelacionadas. O fluxo avança no tempo, rápido ou lento, ordenadamente ou aos trambolhões, $e$ às vezes segue não uma, mas várias seqüencias. Às vezes, as seqüências são concorrentes, outras vezes convergentes ou divergentes, ou ainda sobrepostas. Pensamento é uma palavra aceitável para denotar esse fluxo de imagens. (2000, p.402-3).

Sobre a investigação em torno da imagem, aqui conșiderada a partir de seus suportes físicos, a iconologia e a iconografia, como métodos de investigação da imagem, devem ser lembradas como ferramentas importantes, principalmente com as contribuições de Aby Warburg, Fritz Saxl e Erwin Panofsky.

É claro que a semiótica não se furtou em contribuir para seu estudo. Aliás, todas as tradições de estudos semióticos passam necessariamente por uma reflexão e sistematização de uma teoria dos signos que abarque, obviamente, a questão da imagem. Na semiótica de Charles S. Peirce, a noção de ícone, que se constitui a partir do critério de semelhança em relação ao objeto, aproxima-se mais do conceito de imagem. Entretanto, deve-se ter cuidado ao fazer uso deste conceito, uma vez que o ícone, segundo Peirce, refere-se também a signos de canais não visuạis, envolvendo todo espectro sensorial do homem. Assim, podemos ter ícones acústicos, quando, por exemplo, imitamos o som de um pássaro ou a voz de alguma figura pública.

Ao deslocar sua atenção do signo para o texto, a Semiótica da Cultura fornece-nos uma perspectiva mais adequada para abordar a imagem enquanto um fenômeno cultural. Com as contribuições dos semioticistas da Escola de Tartu-Moscou, passamọ a encarar a imagem não apenas como um signo fechado, mas como um entrelaçamento de fios e tramas, ou seja, pela associação dos seus elementos visuais e sua projeção histórica que uma determinada. imagem, como um produto cultural, deve ser considerada. Por isso, em șuas famosas Teses para um Estudo Semiótico da Cultura, Lotman, 
Ivanov, Toporov, Uspenskij e Pjatigorskij, consensualmente, declaram o texto como uma unidade básica da cultura (1975, p.62). A natureza textual da imagem não a reduz à esfera do verbal; a palavra texto, neste caso, está em consonância com o seu significado original remetendo-nos à idéia de tecido, urdidura ou tapeçaria. Norval Baitello Jr. explica claramente a noção de texto:

Ora, o registro de um determinado signo ou de um grupo de signos, sua permanência ou sua transformação em diferentes momentos perceptivos, constitui um percurso, ou seja, um encadeamento, uma associação de signos, vale dizer, um objeto de natureza narrativa, no qual o significado não se mantém senão globalmente (...). Assim, o tecido não é apenas uma somatória de fios ou fibras, mas a textura que estas fibras produzem. Assim, o texto não é um conjunto, uma somatória de elementos discretos, mas sim o resultado de uma interação de elementos e sua projeção temporal. Um signo único não será portanto um texto se não for visto em um pencurso, em uma relação temporal ou espacial, dialogando consigo próprio ou com outros signos. (1997, p.41-2)

A complexidade do texto ajuda-nos a elucidar a natureza de uma imagem, a partir de sua história e de seus vínculos com uma determinada cultura. Certamente, é esta abordagem semiótica que estará, de forma subjacente, presente na análise que faremos da iconografia cristã. Entretanto, ainda permanece o desafio de lidarmos com um conceito mais preciso e operacional de imagem, que se case com os objetivos deste trabalho.

Em um instigante ensaio sobre a fotografia, o teórico da mídia tcheco Vilém Flusser, que passou boa parte de sua vida em São Paulo, incumbe-se da tarefa de conceituar imagem e o faz com simplicidade e criatividade. Mas, uma vez que sua obra trata essencialmente de fotografia, Flusser se prende à noção de imagem plana, e não se preocupa, além disso, em estabelecer tipologias. Sua reflexão passa também pela instância mental das imagens, ao tentar definir 
imaginaçãa como elemento fundamental na construção e decodificação de imagens. Diz ele logo no início de sua obra:

Imagens são superficies que pretendem representar algo. Na maioria dos càsos, algo que se encontra lá fora no espaço e no tempo. As imagens são portanto, resultado do esforço de se abstrair duas das quatro dimensões de espaço-tempo, para que se conservem apenas as dimensões do plano. Devem sua origem à capacidade de abstraçãa especifica que podemoś chamar de imaginação. No entanto a imaginação tem dois aspectos: se de um lado, permite abstrair duas dimensões dos fenômenos, de outro, permite reconstituir as duas dimensões abstraidas na imagem. Em outros termos: imaginação é a capacidade de codificar fenômenos de quatro dimensões em simbolos planos e decodificar as mensagens assim codificadas. Imaginação é a capacidade de fazer e decifrar imagens. $(2002$, p.7)

É a partir deste pensamento de Flusser que Norval Baitello Jr. nos retrata uma espécie de crise da imaginação diante do excesso de imagens cotidianas a que estamos expostos. É justamente neste trânsito entre imagens internas externas, onde Flusser localiza a idéia de imaginação, que se institui um desequilíbrio. O titanismo e a onipresença das imagens externas diminuiria nossa capacidade de construir novas imagens do mundo e imaginar outras possibilidades, estabelecer novas relações: De tanto serem interpelados, das maneiras mais apelativas e insidiosas, em toda e qualquer hora, em todo e qualquer lugar, com imagens cada vez mais gritantes e repetitivas, nossos olhos já não querem ver... (2003, p.80). Se as imagens são intermediações entre o homem e o.mundo, como diz Flussser, em que medida seriam elas também biombos? É assim que as cidades acabam sendo escondidas pelos outdoors. O não poder. ver por causa da saturação transforma-se em um não querer ver e a crise se instaura no olhar. 
O filósofo e sociólogo alemão.Dietmar Kamper, em $A$ Estrutura Temporal das Imagens, nos diz que nossa órbita ocular é palco de uma derrota secular da visão. A velocidade e saturação de imagens em um universo coberto pelos meios de comunicação seriam os perpetradores dessa derrota. Em um outro texto, Imanência dos Media e Corporeidade Transcendental, Kamper nos pergunta se há algum mundo além dos media, ou se eles já cobriram tudo.

À crise do olhar em razão de um universo tomado por imagens está ligada à fábula de Borges, citada por Baudrillard no início de seu Simulacros e Simulação. A estória nos fala de um rei que encomendou aos cartógrafos de seu reino um mapa que representasse perfeitamete a geografia de seu país. O resultado acabou ficando tão perfeito que a obra acabou cobrindo totalmente o território. Esta fábula serve para Baudrillard nos assegurar que hoje habitamos o mapa e não mais o território, cujos fragmentos apodrecem lentamente sobre a extensão do mapa. (1991, p.8)

Kamper apresenta-nos, na Enciclopédia Antropológica Cosmo, Corpo e Cultura, um sentido ambivalente na origem da palavra alemã equivalente à imagem, bild. Do antigo alto alemão, billid, engloba significados como forma, essência, imagem, cópia ou reprodução. Há, assim, um problema, portanto, desde o início, em que a representação dá lugar à magia, já que bild pode designar a presença de uma essência. Kamper, deste modo, nos diz que, originariamente, a imagem tem como objetivo reproduzir, apresentar e desenhar. Sobre a magia evidenciada na ambivalência do conceito, diz o autor: Esta posição muitável entre uìna ordem mágica da plèia presença na qual a imagem é idêntica àquilo que mostra e uma ordem da representação que teride ao vazio (...) nunca se perdeu de todo (2002). O sacramento da Eucaristia e a veneração de imagens dos santos na igreja são prova evidente de que os vestígios da magia não se perderam.

O que podemos dizer da sacralização das imagens publicitárias, segundo este pensamento? Ao mesmo tempo em que ocorre uma banalização das imagens, devido ao seu excesso em nosso cotidiano, devemos também admitir um esforço em divinizar produtos através de imagens, o que nos leva fatalmente à onipresença do 
espetáculo em nossa sociedade. Trata-se ai da tentativa de recuperar um poder que as imagens rituais exerciam sobre o homem, mesmo que residualmente. O objetivo é, claramente, provocar encantamento e, para tanto, deve-se tentar sobressair diante do gigantismo asśumido pelas imagens no espaço urbano. Outdoors ficam cada vez maiores e acabam inaugurando uma disputa do espaço pelas imagens, como afirma Baitello (2003, p.80). Recentemente, a agência de publicidade DPZ, em um anúncio, fixou um automóvel na superficie de um outdoor em uma avenida da capital paulista, exemplo claro de fazer a imagem confundir-se com o próprio objeto, evidenciando uma intenção mágica. Do mesmo modo, o culto dedicado aos líderes políticos e o patrocínio da cultura de massa à veneração das estrelas do show business mostram a força do encantamento exercido pelas imagens ainda na entrada do século XXI.

Um outro desafio se apresenta ao lidarmos com a questão da representação sígnica da imagem. Sobre isto, vale a pena citarmos a polêmica acerca da natureza da imagem entre o semioticista Winfried Nöth e o respeitado pesquisador Hans Belting, conforme nos relata Benjamin Burkhardt no artigo Controvérsia em Torno de uma Ciência das Imagens. No início de 2004, em um encontro acadêmico na Alemanha, Nöth argumentava haver uma deficiência semiótica nas pesquisas de Belting, em razão deste ignorar a natureza sígnica das imagens, ao passo que este último acusava a semiótica de reduzir a imagem ao conceito de signo, dando a ela um caráter unicamente representacional. Abaixo a lmagem e Todo Poder ao Signo era o provocativo título da conferência de Belting. De fato, a noção de signo torna-se insuficiente para abrigar toda força irradiadora da imagem, sendo por isso que a Semiótica da Cultura privilegiou o conceito de texto. A imagem, enquanto objeto da cultura, já se apresenta como uma unidade complexa, de natureza narrativa, como um encadeamento de elementos que se dialogam, compondo uma história que lhe confere um sentido e uma função cultural. Esta controvérsia, portanto, estaria resolvida se ao invés de um signo, nos defrontássemos com um texto, pois a ambivalência das imagens e o seu poder exercido sobre o homem só podem ser deslindados em uma unidade mínima narrativa e complexa. 
O que são imagens, então? De um ponto de vista da cultura e levando em consideração o aspecto material do objeto, imagens são textos culturais, construídos pelo homem, frutos de sua imaginação, que duplicaram o seu mundo e seu imaginário, dando-lhe formas figurativas ou abstratas nos mais diversos suportes visuais. As diferentes funções e naturezas das imagens, em diferentes épocas, congregam a ambivalência da distância representativa e de sua participação na essência do que está por detrás delas. Representação e presentificação são dois limites (não deixando de observar as inúmeras possibilidades gradativas) entre os quais percorre o poder que as imagens sempre exerceram sobre o homem.

\section{$A$ arqueologia da imagem}

Neste item será analisada apenas a origem das imagens materiais produzidas pelo homem, deixando de lado o problema das imagens mentais, pois este é um fenômeno que transcende, obviamente, o gênero Homo.

Um dos maiores problemas ao nos defrontarmos com a préhistória da humanidade, como nos alerta Lerói-Gourhan, é que lidamos quase somente com dados probabilísticos, o que limita uma reconstituição das práticas, atitudes do homem pré-histórico frente às imagens e do poder nelas investido. Todos estes elementos não são fossilizávéis e, portanto, cabe ao estudioso interpretá-los através de pistas deixadas pelos nossos ancestrais. Outra dificuldade é que denominamos como pré-história um período de longas e sucessivas etapas do processo de evolução humana, que remonta a alguns milhões de anos e que durou até mais ou menos dez mil anos atrás. Estamos tratando, portanto, não de um homem, mas de uma variedade de espécies Homo, que ao longo do tempo foram extintas pela seleção natural até culminarem no Homo sapiens, há cerca de cem mil anos.

A questão da religiosidade do homem pré-histórico está ligada muitas vezes ao problema do surgimento das primeiras imagens, pois delas se extraíam, provavelmente, temas mitológicos, muito embora seja possível identificar a presença de um pensamento religioso antes mesmo do período figurativo no paleolítico superior. 
Uma vez que oterreno é movediço, ao invés de perguntarmos quando surgiu a centelha religiosa na humanidade, seria melhor indagarmos em que etapa do processo evolutivo percebemos sinais de que o homem é religioso. Mircea Eliade, que não é um estudioso da pré-história, objeta a este tipo de questionamento, pois, para ele, a religiosidade não é fruto de uma etapa do processo evolutivo, ao invés disso, ela constitui uma estrutura na mente humana (1978, p.13). Devemos nos lembrar de que a religiosidade, mitos e ritos praticados pelo homem pré-histórico estão profundamente vinculados à questão da emergência da cultura, conforme assinalam Ivan Bystrina e Edgar Morin:

Em seu livro As Religiões da. Pré-história, título que esconde as verdadeiras intenções da obra, Leroi-Gourhan toma como desafio discutir esse tema e responder a esses questionamentos. $\mathrm{O}$ paleontólogo avisa ao leitor, contudo, que em sua análise, justamente por falta de materiais que possibilitem uma separação conceitual, não será feita nenhuma distinção entre religião e magia. De qualquer modo, haveria indícios de detectar a crença em algo transcendente. Assim, Leroi-Gourhan defende que as manifestações e objetos produzidos pelo homem, que não poderiam ser explicados por razões de sobrevivência física da espécie, poderiam apontar para a religiosidade deste homem: a presença do ocre no habitat do homem de Neanderthal é considerada um fato religioso, porque não é explicável por necessidades de sobrevivência material. (s/) d, p.26). Portanto, há motivos claros para atestar o pensamento religioso no homem a partir do paleolítico superior, a partir de cerca de 50 mil anos atrás. Embora faltem elementos suficientes para comprovar uma religiosidade mais tardia, pode-se contudo admiti-la:

Feitas estas reservas, não há nenhuma razão válida para recusar aos antropídeos paleolíticos preocupações de caráter mïsterioso, quanto mais não fosse porque a sua inteligência; da mesma natureza, senão do mesmo nível, da do h@mo sapiens, implica a mesma reação em face do anormal e do inexplicável. $O$ homem, desde as primeiras formas até a nossa, inaugurou e desenvolveu a reflexão, 
ou seja, a capacidade para traduzir em simbolos a realidade material do mundo que o envolvia. A proprie-. dade elementar da linguagem consiste em criar, paralelamente ao mundo exterior, um mundo todo poderoso de símbolos sem os quais a inteligência se revelaria ineficaz. (s/d; p.26)

Ivan Bystrina, amparado no critério de Leroi-Gourhan para detecção do pensamento mágico e religioso no homem, cria o conceito de segunda realidade como o domínio dos mitos, rituais, magia, religião, artes e todas as manifestações que não se explicam por necessidades de sobrevivência material do homem.. O elemento fundante desta segunda reálidade, que, para Bystrina, equivale ao conceito de cultura, seria a consciência da morte: Se esta é obstáculo da primeira realidade (realidade bio-física e técnica do homem, exigindo mecanismos de sobrevivência material), é possível somente superá-la no plano simbólico. Đaí é que se estabelecem os compromissos humanos com os deuses e a magia, que a partir de então vão governar a vida humana. A cultura, neste sentido, é fruto da experiência humana da morte: Os vestígiọs de que o homem pratica rituais de enterro de seus semelhantes há pelo menos 50 mil anos, muitas vezes com acompanhamento de flores juntỏ ao corpo, ápontam também a.presẹça de um rico universo simbólico; tomado já por um pensamento mágico. Em muitos casos, as armas e utensílios eram depositados junto com o morto, o que indicaria, segundo Edgar Morin, uma possível preservação da.identidade depois da:morte Um outro caso interessante são corpos inumados em posição fetal, evidenciando: a crença derenascimento depois da morte As primeiras pistas dos funerais pré-históricos ainda não registram o aparecimento de uma arte figurativa, que começaria a evoluir posteriormente:

A o que Bystrina chama de segunda realidade, Edgar Morin denomina segunda existência o domínio deste universo simbólico. Tạl como Bystrina, Morin também acredita no papel da morte como fundadora deste universo, no decorrer do processo de hominização. Em uma de suas principais obras, O Paradigma Perdido, o autor assim se expressa: 
- Portanto,"tudo nos indica que o Homo sapiens é atingido

-j: pela mórte como por uma catástrofe irremediável que $\therefore$. vai trazer consigo uma ansiedade especifica, âangústia ou o horror da morte, que a presença da morte passa a ser um problema vivo, isto é, que trabalha a sua vida. Tudo nos indica igualmente que esse homem não só recusa

- ‘. essa morté; mas que a rejeita, transpõe e resolve, no mito e na màia. (s/d, p:95)

Antes mesmo do surgimento da arte figurativa, há cerca de 35 mil anos a.C, aparecem já:formas de grafismo. São seqüências de linhas gravadas em pedras e ossos; guardando entre elas a mesma dištância que, para Leroi-Gburhan, são as evidências mais antigas de um comportamento rítmico do homem e assinalam a certeza de que o grafismo se inicia no abstrato e caminha em direção à figuração concreta: Para o autor, este caminho, tantas vezes seguido pelas artes históricas, leva-nos: a admitir que,corresponde a uma tendência geral, a um ciclo de maturação, onde o abstrato esteja realmente na base de uma expressão gráfica. (s/d, 192).

As primeiras imagens figurativas começam a aparecer mais ábundantemente a partir de mais ou menos $30 \mathrm{mil}$, anos atrás, tendo como suporte paredes de grutas e objetos móveis, como armas. Concentram-se, principalmentena Europa, sendo que as imagens parietais encontram-se!basicamente restritas à Espanha; França e sul da Itália: As descobertas da arte paleolítica são relativamente recentẹ e aconteceram quase simultaneamente: a gruta de Chabot (1878) e Altamira; na Espanha:(1879) ${ }^{4}$

4. Achados arqueológiços mais recentes, no Parque Naçional da Serra da Capivara, no Piaui, atestam a presença de figuras antropomórficás em rochas do sítio - Tocá da'Bastiana' que datariam de 30 mil anos. 'A arquéóloga brasileira Niède Guidon, responsável; pelas ;escobertas, publicou em 1986, na ;conceituada - revista Nature, que havia ali vestígios de ocupaçäo humana no continente àmericano de 50 mil anos ătrás. Sua tese tornoüse bàstante polêmica è meio a'comunidade científica; uma vez que refutàva a' hipótese mais aceita de que o continente havia recebido as primeiras migrações humanas há cerca de 12 mil anos pela passagem do estreito de Bering. Infórmaçöes mais dètalhadas podèm ser encóntradàs no infórmátivo da sóciedade Brasileirá pará ó Progresso

:' da Ciência: ẇww.jornaldaciencia.org.br. 
Seriam as pinturas e inscrições parietais e móveis do paleolítico frutos da capacidade imaginativa do artista ou manifestações religiosas? A dificuldade de responder a esta: questão nasce justamente do fato de nosso olhar sobre a pré-história se contaminar de noções atuais de arte e' religião. Poderíamos, neste instante, concordar com Edgar Morin, segundo o qual os fenômenos mágicos são potencialmente estéticos e os fenômenos estéticos são potencialmente mágicos (s/d, p.98). Se se separar o artista do homem religioso, a discussão perde solidez, conforme nos alerta Leroi-Gourhan. Suas mensagens, através das figuras, respondem a uma necessidade, ao mesmo tempo fisica e psíquica, de assegurar a apropriação do universo pelo individuo ou grupo social, de realizar a inserção do homem através do aparelho simbólico no campo movediço e aleatório que o envolve (s/d, 81-2). Este aparelho simbólico não pode ser despido de um pensamento mítico e mágico. Defrontamonos, agora; com as primeiras evidências de uma relação mágica entre homem e imagem; e o suporte para as primeiras figuras desenhadas são principalmente as paredes de grutas.

Quais eram os temas mitológicos inscritos nas cavernas que este homem nos deixou? Os estudos e análises empreendidos por Leroi-Gourhan são uma das principais contribuições de sua obra. A partir de um inventário destas figuras, o paleontólogo francês constatou três núcleos temáticos que envolvem toda a arte no paleolítico, a saber: animais, seres humanos e signos. Estes últimos, apesar de sua natureza abstrata, são considerados pelo autor como símbolos sexuais do masculino e do feminino. Uma constatação impressionante é que não há muitas variações de sentido nessas figuras, mesmo cobrindo um período que vai de 30 mil anos a. C até nove mil anos a. C. As análises e associações feitas por Leroi-Gourhan permitem concluir que animais (cavalo e bisonte aparecem com abundância), figuras humanas e signos, que aparecem muitas vezes com o seu par oposto, constituem um tema binário, com representações simbólicas do masculino e do feminino. Uma das tarefas do autor é cruzar os núcleos e tentar decifrar seus temas, o que nos leva para um campo de dados probabilísticos. Apesar das sombras que pairam sobre a religiosidade na pré-história, o paleontólogo francês conclui 
que a constância dos temas, durante um longo período, dão provas de um sistema simbólico de crenças mais complexo do que se imaginara. Assim afirma ao final de seu livro:

Faltam-nos ainda elementos para descrever o progressivo enriquecimento e as variações regionais do aparelho mitográfico entre o fim do Solutrense e o Madalenense Médio, entre 15.000 e 12.000. Conjuntos admiravelmente homogêneos (...) ateștam que nesta época, entre o Loire e os Pirineus, não só o grupo central se tornou muito. denso, com a sua combinação de pares de animais emparelhados por espécies diferentes, como ainda as figuras de homens compósitos, os felinos, os rinocerontes e os animais sem cabeça que povoam os fundos, criaram uma retaguarda densa de símbolos vinculados à zona mais íntima do mistério. (s/d, 134).

A conclusão do autor acerca do binarismo da arte paleolítica converge com a posição de Ivan Bystrina de que o processo de codificação semiótica mais arcaico é o binário. Dividir o mundo em dois representaria o modo pelo qual o homem começa a organizar todo o aparato simbólico que o envolve. As percepções do masculino e do feminino, da noite e do dia, das sensações de prazer e dor, presentes na realidade biofísica do homem, inspirariam a formação de textos culturais com características duais. No processo de desenvolvimento ontogênico do ser humano, Harry Pross trata semelhantemente das experiências pré-predicativas do claro/escuro e dentro/fora, constituindo-se como as raízes da experiência do homem. Por ser justamente a mais arcaica, a divisão binária é o mais forte modo de codificar a realidade. No Cristianismo, a idéia do mal, contrapondo-se a Deus, encarna-se na figura do Diabo ${ }^{5}$, no cinema e nas novelas, narrativas que possuem um acirrado dualismo são as

5 A existência do Diabo, ou de um mal encarnado, näo está muito clara no Antigo Testamento. Após o cativeiro babilônico dos judeus e o conseqüente contato com o Masdeísmo e o Zoroastrismo, suas referências se tornam claras e abundantes no Novo Testamento. Portanto, quando nasce o Cristianismo, sua 
que fazem maior sucesso, pois fácilitam a absorção da mensagem pelo telespectador.

Além do binarismo dominante nas figuras paleolíticas, podemos entrever também um compromisso mágico na relação entre homem e imagem, a partir do qual o homem estende seu domínio sobre a natureza. Embora faltem elementos seguros e comprobatórios, Leroi-Gourhan admite que o maior argumento em favor deste comportamento está nas imagens feridas de cavalos ou bisontes. Isto poderia indicar um ritual a fim de garantir o êxito da caça. Curioso, porém, é que às feridas' aparecem somente em $4 \%$ das figuras de animais, o que não exclui a possibilidade de que $o$ ferimento de um animal valeria também para todo o rebanho. $O$ que está em discussão é a presença de uma mentalidade mágica que manipula símbolos, com o objetivo de suprir eficazmente suas necessidades cotidianas. Nas palavras de Jacques Maritain, o signo mágico não apenas faz os homens conhecerem, ele faz as coisas serem; é uma causa eficiente em si mesma (apud. Nöth, 1996, p.38). A magia implica em uma crença de que as coisas possuem uma dupla existência, na qual os limites entre o signo e 0 objeto representado encontram-se difusos. O cavalo está presente em sua imagem, ou melhor, a imagem mental evocada pelo significante pode se confundir com o próprio cavalo. É assim que passamos a projetar nossas visões sobre o mundo exterior até ao ponto em que ambos se misturam. A partir.do grafismo e da arte figurativa pré-histórica, Edgar Morin vê traços bastante convincentes deste encantamento do mundo.

Portanto, o que o grafismo mural nos revela é a ligação imaginária com o mundo. Por um lado, a palavra, o sinal, o símbolo, a figuração vão ininterruptamente re-apresentar ao espírito, mesmo na ausência deleș, os seres e as coisas do mundo exterior e, num certo sentido, esses seres e essas coisas passam a ser dotados de um poder de invasão. Por outro lado, são as imagens mentais que invadem o mundo exterior. É nesta confusão, e para transpor esta

figura já havia sido fortemente caracterizada. Sobre a história do Diabo e as forma que ele assume no Cristianismo, remetemos o leitor ao livro "O Diabo no Imaginário Cristão", de Carlos Roberto F. Nogueira. 
confusãó, que se constroem o mito e a magia, quer dizer, uma organização ideológica e prática da ligação imaginária com o mundo $(\mathrm{s} / \mathrm{d}, 100)$.

Os exemplos dessa maneira mágica de pensar o mundo não se esgotam no paleolítico, muito menos nas culturas primevas côntemporâneas, pois encontram-se também nos domínios das diversas formas de religiosidade contemporânea. A própria questão do uso dos ícones religiosos evidencia, em muitos casos; este compromisso mágico estabẻlecido com à imagens. O antropólogo James Frazer, imbuído de uma visãó positivista assim se expressa a respeito da magia: o homem confundiu a ordem de suas idéias com a ordem da natureza, é assim imaginou que o controle que tem, ou parece ter," sobre o's seus pensamentos permitiu-lhe exercitar um controle correspondente sobre as coisas. (apud. Nöth,1996, p.40)

Ao problema da imagem está sempre ligadà a questão do duplo: Espelho, simulacró, figưração: a magia irrompe com intensidade variável, independentemente da cultura; tempo ou dos suportes que a imagem toma, questionando o homem sobre os: limiares semióticos da representação. Muitas vezes, a imagem é tomada como mentira e. se encontra diante da fúria dos iconoclastas, mas a magia volta, pois os fenômenos estéticos são potencialmente mágicos, conforme nos lembra Morin. Desde Narciso (a ele está associado o termo narcose) o encantamento ainda persiste. Mas com ele convivem contraditoriamente a saturação e a banalização em uma época coberta pelas mídias.

\section{Bibliografia}

BAITELLO Jr, Norval. 1997. O animal que parou os relógios. São Paulo: Annablume.

BAUDRILLARD, J. 1991. Simulacros e simulação. Lisboa: Relógio D'água.

BELTING, H. 1994. Likeness and presence: a history of the image before the era of art. Chicago, London: The University of Chicago Press. 
BENJAMIN, W. 1969. Iluminations. New York: Schocken Books.

BURKHARDT, B. 2004. Der streit um die wissenschaft der bilder. Disponível em www.telepolis.de/deutsch/inhalt/konf/16781/1.html. Acesso em 20 de fevereiro.

BYSTRINA, I. 1995. Tópicos de semiótica da cultura. São Paulo: editado pelo Centro Interdisciplinar de Semiótica da Cultura do Programa de Pós-Graduação em Comunicação e Semiótica (PUCSP).

2002. Cosmo, corpo, cultura. Enciclopédia antropológica. Christoph Wulf (org.). Milano: Mondadori.

CONTRERA, M. S. e HATTORI, O. T. (org.). 2003. Publicidade e cia. São Paulo: Pioneira Thompson Learning.

ELIADE, M. 1978. História das crenças e das idéias religiosas, v.1. Rio de Janeiro: Zahar.

FLUSSER, V. 2002. Filosofia da caixa preta. Rio de Janeiro: Relume Dumará.

KAMPER, D. 2002. Estrutura temporal das imagens. Disponível em: $<$ http//www.cisc.org.br. Acesso em: 20set.

1997. Os padecimentos dos olhos. In: Ensaios de Complexidade. Porto Alegre: Sulina:

LEROI-GOURHAN, A. s/d. As religiões da pré-história. Lisboa: Edições 70.

s/d. O gesto e a palavra: técnica e linguagem. Lisboa: Edições 70.

MORIN, E. s/d. O paradigma perdido: a natureza humana. Lisboa: Europa-América.

NOGUEIRA, C. R. F. 1986. O diabo no imaginário cristão. São Paulo: Ática.

1996. Semiótica da magia. In: "Dossiê Magia", Revista da USP, n³1. São Paulo: USP, Setembro, outubro e novembro.

PROSS, H. 1980. Estructura simbólica del poder. Barcelona: Gustavo Gili. 